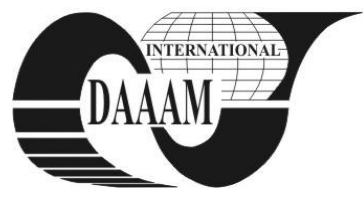

Annals of DAAAM for 2011 \& Proceedings of the 22nd International DAAAM Symposium, Volume 22, No. 1, ISSN 1726-9679 ISBN 978-3-901509-83-4, Editor B. Katalinic, Published by DAAAM International, Vienna, Austria, EU, 2011 Make Harmony between Technology and Nature, and Your Mind will Fly Free as a Bird Annals \& Proceedings of DAAAM International 2011

\title{
ERGONOMIC PROGRAM AS A TOOL FOR ENHANCING EFFICIENCY OF HUMAN WORK
}

\author{
KYZEK, J[an] \& HATIAR, K[arol]
}

\begin{abstract}
The current global market conditions in the efforts of competitiveness in relation to requirements of sustainability appear the question of increasing human work efficiency through ergonomic programs. This problem is topical also in Slovakia after the process of industrial transformation in framework of the EU accession process; we have prepared a project in which we focused on acquiring the knowledge applicable in Slovakia and in countries after process of transformation of industry as well by ergonomic analysis.

Key words: ergonomics, ergonomics program, nordic questionnaire
\end{abstract}

\section{INTRODUCTION}

That the employee could make an effective job performance must be to ensure appropriate working conditions. The work process applied to employee a number of factors that affect their work performance, work quality, and not least his health. We realize that effective, sustainable business performance, we can only expect from a healthy, rested and satisfied employees. We are witnessing a variety of efforts to secure a sustainable level of efficiency of human labor. One possibility is broad approach which is characterized by reducing the content of work, high work rate, overtime and low wages. In developed countries dominated by a strong approach to ensuring the sustainable long-term effectiveness of human labour through a systematic ergonomics programs based on local principles of ergonomics (eg Cohen et al., 1997). We came to believe that such an approach is better just through its focus on sustainability. For this reason we consider it necessary to find out as much about the application of ergonomic programs in developed EU countries, so that we gain knowledge about where we assume that it could be beneficial for Slovakia as well as for other states after the transformation industry. For this purpose, we focused on collecting data for ergonomic analysis in selected EU countries, enabling us to assess the effectiveness of the ergonomic programs and initiatives for use in the programs in companies in Slovakia. In the above analysis we will use evidence of collaboration with the University of Iowa in the U.S. ( Zimmermann et al., 1998) in framework of international project "Transformation Industry in Slovakia through Participatory Ergonomics.

\section{DATA FOR PROPOSED ERGONOMIC ANALYSIS}

Ergonomic analysis allows us to assess in selected workplaces on the basis of prevalence and severity of MSS problems in employees, developed through effect of negative factors of work and working environment. As an indicator of shortcomings of workplace in terms of ergonomics we applied occurrence, location and intensity of MSS problems.

This study is focused on enterprises in the industrial cleaning equipment and because of that area in Slovakia we have a credible long-term experience.

\begin{tabular}{|l|c|c|}
\hline STATES & $\begin{array}{c}\text { Number of } \\
\text { Enterprises }\end{array}$ & $\begin{array}{c}\text { Number of filled } \\
\text { out questionnaires }\end{array}$ \\
\hline Austria & 1 & 10 \\
\hline Czech Republic & 1 & 10 \\
\hline Italy & 3 & 30 \\
\hline Norway & 1 & 10 \\
\hline Portugal & 2 & 15 \\
\hline Slovak Republic & 6 & 120 \\
\hline Switzerland & 3 & 70 \\
\hline Summary & $\mathbf{1 7}$ & $\mathbf{2 6 5}$ \\
\hline
\end{tabular}

Tab. 1 Number of persons involved to this study, which returned filled out „Nordic Questionnaires" in enterprises according to countries

In framework of data collection we focused on obtaining of as great number of data as possible from enterprises around the world.

So far we have contacted companies in 27 countries around the world. Based on interviews with representatives of these companies, we were allowed to receive data through questionnaires together in 17 companies (Table 1). We sent out 350 questionnaires together, which we have so far returned 265 completed.

So far we have contacted enterprises from 27 countries around the world. Based on interviews with representatives of these companies, we were allowed to receive data through questionnaires together in 17 companies (Table 1).

While we sent out 350 questionnaires, of which we have so far returned 265 completed (Response Ratio $=75,7 \%$ ).

In addition to these enterprises were contacted and other businesses in the following states, which are not involved to cooperation only through provided information on the basis of personal interviews. These are companies from the following countries: Argentina, South Korea, Morocco, Tunisia, Egypt Turkey, England, Finland, Brazil USA, Germany, Denmark Russia, Slovenia,. Bulgaria, Greece, Spain, Poland, Hungary.

\section{METHOD ON DATA COLLECTION AND PROCESSING}

In this study, we applied retrospective cohort study design adapted to ergonomic analysis.

Data for this study, we obtained through special questionnaires and interviews with representatives from participating companies. Some companies allowed us to do photo documentation directly in operations.

Nordic Questionnaire and special questionnaire which we developed, they meet following requirements:

- They have a logical structure (taking into account the nature of the data, database structure, and anticipated requirements for data processing).

- Allow easy data entry and processing.

- Shortest possible time to complete:

- Smallest possible form (max. of one two-sided page), 
- Attractive, uncluttered layout with graphic aids where appropriate,

- Simple and clear questions,

- Clear and unambiguous alternative answers.

As a basic method of data collection for this study we used modified Nordic Questionnaire (Kuorinka and Johnson, 1987; and Zimmermann et al., 1998) meets these requirements and consists of four sections. Problems, of musculoskeletal system such as pain and numbness, can be considered precursors to musculoskeletal system disease (MSD's) and in our study serve as indicator shortcomings of workplace from point of view of ergonomics, (Van Wely 1970 and Rosecrance et al., 2002), or more positively stated, as opportunities for improvement from an ergonomics point of view. Valid and reliable data regarding the musculoskeletal health status of employees are essential to justifying, formulating, implementing, and evaluating ergonomic programs. Improved health status is a fundamental measure of improved working conditions and related increases in productivity.

The modified Nordic Questionnaire that has been developed for use in our ergonomic programs.

The first section addresses basic demographic information, body characteristics, and parameters describing the work performed by each respondent. Some of these variables are collected as potential confounders for the occurrence of MSD's. This section contains quantitative continuous parameters such as: age, years in present occupation, body height, and body weight. Also included are other parameters such as gender, questions related to work schedule, and primary working posture.

The second section of the questionnaire addresses the 12month period prevalence of work-related MSD complaints, expressed as simple Yes/No answers. This part of the questionnaire is a modification of the Nordic Questionnaire ${ }^{(2,4)}$ and consists of questions referring to nine anatomical areas (neck, upper back, low back, shoulders, elbows, wrists/hands, hips/thighs, knees and ankles/feet area). Subjects answer "yes" or "no" to the question, "During the last 12 months have you had a job-related ache, pain, discomfort, etc." This is a list of the nine different body areas and an accompanying diagram to help identify them. When a respondent marks "yes", that a work - related MSD symptoms has occurred, he or she is instructed to answer "yes" or "no" in the next column as well. That question is: "During the last 12 months have you seen a physician (M.D., Osteopath and Chiropractor) for this condition?" A positive question in this column prompts the respondent to answer the following question in the third column, "Has this condition caused you to miss work in the last 12 months?"

The third section of the questionnaire addresses the employee's perception of 15 different job factors and their perceived contribution to musculoskeletal complaints. The respondent is given a descriptive list of 15 job factors and asked to indicate on a scale $0-10(0=$ no problem, $10=$ major problem) how much (if at all) they think each factor is a "problem" for them. A " 1 " or greater is coded as "positive" for that factor while a " 0 " response is coded as "negative" for that factor.

The fourth section of the questionnaire provides a respondent the opportunity to identify him- or herself and to provide informed consent for access to personal medical records. This information is then used to verify the worker's responses regarding physician visits from the second section of the questionnaire.

\section{PRELIMINARY RESULTS}

Data obtained from enterprises are gradually stored to the database. We assume that in the near future we can, for the purposes of our analysis obtain more data.

We assessed only a few points from personal interviews with representatives of selected enterprises from the above countries recently. Above mentioned persons belongs mostly to members of top management selected enterprises (owners, directors respectively General Managers of enterprises).

Preliminary we found that:

- Interviewed representatives from 81 different companies were not willing to answer 74 representatives.

- It has been shown that the majority of interviewed representatives have a good knowledge of ergonomics.

- Up to 59 representatives know what ergonomics is.

- 37 of 74 companies known more to describe the essence of ergonomics.

- Only 12 companies have detailed knowledge of ergonomics, which applies in practice.

\section{CONCLUSION}

Based on preliminary results can be assumed that we were able to get reliable information on the implementation of ergonomics and ergonomic programs in the developed countries in the sustainable increasing the efficiency of human labour in the developed EU countries. Preliminary results interviews with selected members of top management of enterprises show that they generally appreciate the contribution of ergonomic and systematic solution efficiency of human labour. So far studies have shown that the "Nordic Questionnaire" is a suitable tool for ergonomic analysis of working conditions and an assessment of gaps in service. We believe that the evidence so obtained will be useful in finding opportunities for sustainable human work efficiency in enterprises not only in Slovakia, but also in enterprises States that have undergone the process of industrial transformation.

\section{ACKNOWLEDGEMENTS}

This work was supported by KEGA - 3-7285_09 Content, Integration and Design University Textbook "Specialized Robotics Systems in Print and Interactive Modules".

\section{REFERENCES}

Cohen, L.C., Gjessig, CH.C., Fine, L.J., Bernard, P.B., McGlothlin, J.D. (1997) Elements of Ergonomics Programs: A Primer Based on Workplace Evaluation of Musculoskeletal Disorders. U. S. Department of Health and Human Services. Public Health Service, Centers for Disease Control and Prevention, NIOSH, No. 97-117, pg 133Cincinnati, DHHS (NIOSH) Publication

Kuorinka, I., Johnson, B. (1987) Standardized Nordic Questionnaires for Analysis of Musculoskeletal Symptoms. Applied Ergonomics. $18,1987,3$, pp. $233-237$

Rosecrance JC, Ketchen KJ, Merlino LA, Anton DC, Cook TM. (2002) Test-retest reliability of Self-Administrated Musculoskeletal Symptoms and Job Factors Questionnaire Used in Ergonomics Research. Applied Occupational and Environmental Hygiene. 17 (9) 2002, pp 1-9, 2002

Van Wely, P. (1970) Design and Disease. Applied Ergonomics, 1, 1970, 5, pp. 262 - 269

Zimmermann CL, Hatiar KM, Cook TM. (1998) A comparison of work-related musculoskeletal disorders among operating engineers in the United States and Slovakia. Central European J Occup Environ Med 4 (3) 1998, pp 232-246 